\title{
Evidence for the evolution of reduced mycorrhizal dependence during plant invasion
}

\author{
Elizabeth K. Seifert, ${ }^{1,3}$ James D. Bever,,${ }^{1,4}$ and John L. Maron ${ }^{2}$ \\ ${ }^{1}$ Department of Biology, Indiana University, Bloomington, Indiana 47405 USA \\ ${ }^{2}$ Division of Biological Sciences, University of Montana, Missoula, Montana 59812 USA
}

\begin{abstract}
Introduced species inevitably experience novel selection pressures in their new environments as a result of changes in mutualist and antagonist relationships. While most previous work has examined how escape from specialist enemies has influenced herbivore or pathogen resistance of exotic species, post-introduction shifts in exotic dependence on mutualists have not been considered. In a common environment, we compared dependence on AM fungi of North American and European populations of Hypericum perforatum (St. John's Wort), a forb native to Europe. Introduced North American populations responded less to inoculation with AM fungi than did European populations. Root architecture was strongly correlated with mycorrhizal response, and introduced populations had finer root architecture than native populations. Finally, introduced populations exhibited decreased root and increased reproductive allocation relative to European populations, consistent with a transition to a weedier life history; however, biomass allocation patterns were uncorrelated with mycorrhizal response. These findings are the first demonstration of a genetically based reduction of mycorrhizal dependence and shift in root architecture in an introduced species.

Key words: Arbuscular mycorrhizae; biological invasions; exotic plants; Hypericum perforatum; mutualism; mycorrhizal dependence; rapid evolution; root architecture; St. John's Wort.
\end{abstract}

\section{INTRODUCTION}

Introduced organisms inevitably encounter a novel suite of competitors, predators, pathogens, and mutualists in their new ranges. The interaction of exotic species with antagonists and mutualists in recipient communities is important in understanding both exotic success and invader impacts on native assemblages. Most research that has examined interactions between exotic and native species in recipient communities has done so from an ecological perspective. However, there is a growing appreciation that novel selection pressures imposed by an altered set of biotic interactions in the introduced range can lead to rapid, evolutionary changes (Baker 1974, Blossey and Nötzold 1995, Sakai et al. 2001, Lee 2002, Bossdorf et al. 2005). While the influence of these evolutionary changes in phenotype on the ultimate abundance that exotic species attain is unclear, adaptation to local conditions may be crucial in determining colonization success.

Most studies of rapid evolution in exotic-plant populations have focused on how changes in a plant's herbivore or pathogen community affect plant resistance or growth (e.g., Siemann and Rogers 2001, Blair and

Manuscript received 29 February 2008; revised 17 June 2008; accepted 15 July 2008. Corresponding Editor: J. N. Klironomos.

${ }^{3}$ Present address: Department of Ecology and Evolutionary Biology, Rice University, Houston, Texas 77005 USA.

${ }^{4}$ Corresponding author. E-mail: jbever@indiana.edu
Wolfe 2004, Maron et al. 2004a). The evolutionary response of exotic plants to changes in their mutualist assemblage has received considerably less attention, despite the importance of mutualists to pollination, dispersal, and nutrient acquisition (Richardson et al. 2000). The fact that some plant groups, such as the Orchidaceae, are underrepresented in the invasive flora of the world despite widespread cultivation (Pyšek 1998) has suggested that the limited invasion potential of these species may be attributable to the absence of highly specialized pollinators (Richardson et al. 2000). However, for plant species that rely on more generalized mutualisms, the absence of native mutualists in a plant's introduced range may have little effect on its invasion success (Mitchell et al. 2006). Consequently, many plants that rely on more generalized mutualisms do not appear to experience barriers to invasion.

One widespread generalized mutualism involves plants and arbuscular mycorrhizal (AM) fungi, which are generally thought to facilitate plant nutrient acquisition, particularly of phosphorus. Although plant-AM fungal interactions are often beneficial to plants, the relationship between individual AM fungal species and individual plant species can range from parasitism to mutualism (Johnson et al. 1997, Bever 2002, Klironomos 2003). The generalized nature of plant-mycorrhizal associations and cosmopolitan distribution of AM fungi suggest that exotic plants should associate with AM fungi similarly in their native and introduced ranges. Thus, provided they do not exploit 
AM fungi in an unconventional manner (Marler et al. 1999), it is not clear that exotic plants necessarily benefit or suffer as a result of changes in mycorrhizal associations in their introduced ranges (Richardson et al. 2000, Reinhart and Callaway 2006). Even so, some introduced species have been found to be generally less dependent on AM fungi than co-occurring native species (Vogelsang et al. 2004, Vogelsang and Bever 2009). However, differences in mycorrhizal dependence between native and introduced populations of the same species have never been studied. Here, we investigate the mycorrhizal dependence of native European and introduced North American populations of Hypericum perforatum L. (St. John's Wort). We also evaluate other post-introduction changes in life-history traits to determine if there is any indication of simultaneous selection for weedy characteristics and reduced mycorrhizal dependence.

\section{Methods \\ Study system}

Hypericum perforatum is a short-lived perennial forb native to Europe, North Africa, and Asia that typically inhabits old fields, roadsides, and other disturbed sites. It has been introduced to numerous regions of the world, including North America, Australia, and South Africa. Hypericum perforatum was observed in eastern North America as early as 1780 (Muhlenberg 1793), spread across the continent through the 1800s, and was found in California by the early 1900s (Sampson and Parker 1930).

Hypericum perforatum is known to associate with arbuscular mycorrhizal (AM) fungi in both its native European and introduced North American ranges (Moora and Zobel 1998, Klironomos 2003). It produces most of its seed apomictically, meaning that maternal siblings are likely to be clones (Mayo and Langridge 2003, Pank et al. 2003).

\section{Experimental design}

We determined if native and introduced genotypes of $H$. perforatum differed in their mycorrhizal responsiveness by growing plants in sterilized soil that was either inoculated with a strain of AM fungi or left uninoculated. We inoculated pots with a Glomus mosseae culture established by J. Bever from a grassland in Northern Illinois (USA). Glomus mosseae is a common AM fungus occurring in both North America and Europe and is known to be growth promoting across a range of phosphorous availabilities (Vogelsang et al. 2006). Inoculum was grown with Sorghum bicolor (L.) Moench in a 1:1 sand: soil mixture in an Indiana University (Bloomington, Indiana, USA) greenhouse for six months, dried, and stored at $4^{\circ} \mathrm{C}$ until use. We prepared the inoculum for use in this study by cutting the roots of $1 \mathrm{~L}$ of $G$. mosseae culture into small fragments and incorporating them into $10 \mathrm{~L}$ of a $1: 1$ mixture of sterilized sand and Indiana field soil.
We used $H$. perforatum seed from 14 European (native) and 15 North American (introduced) populations, collected in 1998 and 1999, as described in Maron et al. (2004b; Appendix). Seed from six maternal families per population was planted in sterilized potting soil and stratified at $4^{\circ} \mathrm{C}$ for seven days before seeds were germinated on a mist bench in an Indiana University greenhouse. Two four-week-old seedlings from each maternal family were transplanted into Deepots (Steuwe and Sons, Corvallis, Oregon, USA) containing $500 \mathrm{~mL}$ of a 1:1 mixture of sterilized sand and Indiana field soil that tested at $9.5 \mathrm{ppm}$ available phosphorous (Vogelsang et al. 2006). Of each maternal pair, one seedling was transplanted into a pot containing $50 \mathrm{~mL} \mathrm{G}$. mosseae inoculum, and the other was transplanted into a pot containing an additional $50 \mathrm{~mL}$ of the sterilized sand and soil mixture. Uninoculated pots were supplemented with $100 \mathrm{~mL}$ of a non-AM fungal filtrate produced from the inoculum to control for differences in soil flora.

Plants were grown in a heated greenhouse with a 12-h day length for six months before reproductive structures were harvested. We then divided plants into aboveground and belowground portions and washed the soil from the roots. Reproductive ratio was calculated as reproductive biomass/total biomass. Roots were stored at $4^{\circ} \mathrm{C}$ for a maximum of four days before morphological analysis. Root and shoot portions were then dried at $65^{\circ} \mathrm{C}$ for $48 \mathrm{~h}$ and weighed. A 0.25 -g subsample of roots from all inoculated and 20 uninoculated plants was rehydrated, cleared in potassium hydroxide and stained with trypan blue. Percentage AM fungal colonization was determined using standard methods (McGonigle et al. 1990).

Before drying, we removed two additional subsamples from each root system for morphological analysis with WinRhizo image analysis software (version 2005c; Régent Instruments 2005). Each subsample was spread out in water to minimize root overlap and scanned using a desktop scanner. Root length, average diameter, number of branches, and number of tips were then determined using WinRhizo. As branch and tip counts are necessarily related, they were averaged to provide a more accurate assessment of root branching patterns. Each root subsample was separately dried and weighed, but included in the total belowground biomass measurement.

\section{Statistical analysis}

Differences in biomass, allocation patterns, and root morphology between AM fungal treatments, continents, populations nested within continent, and their interactions were analyzed with a three-way analysis of variance using the general linear model procedure of SAS (SAS Institute 2003). Root: shoot ratio and branching were log-transformed to meet the assumptions of the ANOVA. We treated continent and AM fungal inoculation as fixed effects, and population within continent and the interaction of population 
TABLE 1. ANOVA results of the effects of arbuscular mycorrhizal fungi inoculation (AMF), continent of origin, population, and their interactions on total biomass, root: shoot ratio, reproductive ratio (reproductive biomass/total biomass), branching ([no. branches $/ \mathrm{mm}+$ no. tips $/ \mathrm{mm}] / 2$ ), and average root diameter of Hypericum perforatum.

\begin{tabular}{lrccccc}
\hline \hline \multicolumn{1}{c}{ Effect } & df & Biomass SS & Root:shoot SS & Reprod. ratio SS & Branching SS & Diameter SS \\
\hline AMF & 1 & $696.158^{* * * *}$ & $3.553^{* * * *}$ & $0.039^{* *}$ & $0.120^{* * *}$ & $0.024^{* * * *}$ \\
Continent $\dagger$ & 1 & $29.487^{\mathrm{NS}}$ & $3.013^{*}$ & $0.267^{* *}$ & $0.168^{*}$ & $0.009^{* *}$ \\
Continent(population) + & 27 & $404.051^{* * * *}$ & $18.815^{* * * *}$ & $0.905^{* * * *}$ & $0.765^{\mathrm{NS}}$ & $0.025^{*}$ \\
AMF $\times$ continent & 1 & $20.180^{* *}$ & $0.001^{\mathrm{NS}}$ & $0.006^{\mathrm{NS}}$ & $0.055^{\mathrm{NS}}$ & $0.002^{\mathrm{NS}}$ \\
AMF $\times$ continent(population) & 27 & $68.435^{\mathrm{NS}}$ & $1.025^{\mathrm{NS}}$ & $0.090^{\mathrm{NS}}$ & $0.419^{*}$ & $0.013^{*}$ \\
Error & 271 & 2690.317 & 47.891 & 1.066 & 2.406 & 0.085 \\
\hline
\end{tabular}

Note: Root: shoot and branching were natural-log-transformed to meet the assumptions of the ANOVA. "SS" stands for the sums of squared deviations.

$* P \leq 0.05 ; * * P \leq 0.01 ; * * * P \leq 0.001 ; * * * * P \leq 0.0001 ; \mathrm{NS}$, not significant.

$\dagger$ Tested using population $\times$ continent as the error term.

$\$$ Tested using population $\times \mathrm{AMF} \times$ continent as the error term.

within continent and inoculation as random effects. Treating these as random effects allowed us to test for patterns that would persist if we randomly selected 15 new populations from the two continents. While there were no significant differences in seed mass between North American and European populations (J. L. Maron, unpublished data), initial plant size was nevertheless included as a covariate in all analyses to ensure maternal effects were accounted for and statistically minimized.

We were primarily interested in differences between continents, which we tested using the population $\times$ continent interaction as the error term. We were also interested in variation in mycorrhizal response between continents, which was tested using the AM fungal inoculation $\times$ continent interaction, with the AM fungal inoculation $\times$ continent $\times$ population interaction as the error term. Mycorrhizal response was calculated as follows: (inoculated biomass - uninoculated biomass)/ uninoculated biomass.

Multiple phenotypic responses to invasion may be a consequence of independent responses to parallel selection pressures or correlated responses resulting from underlying genetic correlations. While we cannot separate genetic correlation within populations from correlations driven by local greenhouse environment (because maternal lines were not replicated), our design allows broad-sense between-population genetic correlations to be evaluated. Thus, phenotypic correlations among population means represent genetic correlations resulting from either pleiotropic effects of individual genes or interpopulation linkage disequilibrium. Interpopulation linkage disequilibrium may be more substantial between populations than within populations because of potential parallelism in selection pressures across environments. In calculating our interpopulation correlations, we first removed the maternal effect as measured by initial size and the differences between continents using analysis of covariance using the general linear model procedure of SAS (SAS Institute 2003). Comparisons of the resulting residuals were then unconfounded by initial size differences and average differences between continents. Pearson product-mo- ment correlations were calculated between the residuals of mycorrhizal response, root architecture, and biomass allocation with the significance tested using $t$ tests (Sokal and Rohlf 1995).

\section{Results \\ Mycorrhizal infection}

As expected, inoculation led to high levels of arbuscular mycorrhizal (AM) fungal colonization $(19.3 \% \pm 0.8 \%$ [mean $\pm \mathrm{SE}])$, while the control treatment was rarely colonized with fungi $(0.25 \% \pm$ $0.17 \%$ ), which could not be confirmed to be AM fungi. Within the inoculated plants, AM fungal colonization was not significantly different between continents $\left(F_{1,134}\right.$ $=2.41, P=0.13$ ).

\section{Biomass}

Plants grown in soil inoculated with AM fungi were consistently larger than those grown in uninoculated soil (Table 1, Fig. 1). The magnitude of the positive response of plants to mycorrhizal inoculation differed by continent; inoculation had a greater effect on the biomass of native European populations than it did on introduced North American populations (AMF $\times$ continent interaction, Table 1, Figs. 1 and 2a). This effect was significant despite a broad range of mycorrhizal responses among populations within each continent (Fig. 2a). Across treatments, there was no difference in biomass between native European and introduced North American plants (Table 1).

\section{Root morphology}

European populations generally had coarser root systems, with larger average root diameter and less branching than North American populations (Table 1, Fig. 2b, c). Mycorrhizal inoculation resulted in greater average root diameter and branching relative to uninoculated plants (Table 1).

\section{Allocation patterns}

North American populations allocated more than twice as much biomass to first-year reproduction than 


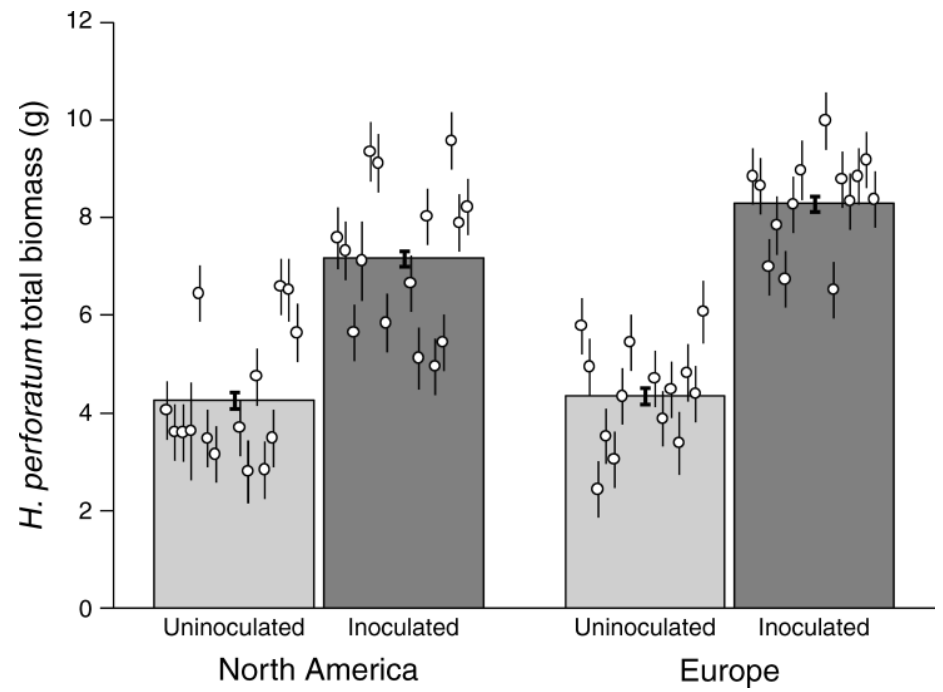

FIG. 1. Total biomass of Hypericum perforatum plants from North America (introduced) and Europe (native) when inoculated with AM fungi and when uninoculated. Circles represent population means; both sets of error bars are \pm SE. Total biomass did not differ between introduced and native populations; however, there was a significant interaction between continent and mycorrhizal inoculation. did European populations (Table 1, Fig. 3a). Introduced $H$. perforatum also allocated less biomass to their roots than European populations (Table 1, Fig. 3b). Inoculated plants allocated more biomass to first-year reproduction and less to belowground biomass than uninoculated plants (Table 1).

\section{Interpopulation genetic correlations}

Mycorrhizal response was significantly correlated with root branching in sterile soil $(r=-0.48 ; P=0.009$; Fig. $4 \mathrm{a})$, in that populations with less branching were more responsive to inoculation. Mycorrhizal response was not correlated with average root diameter. There were no significant correlations between both mycorrhizal response and root architecture and either root: shoot ratio or reproductive allocation. However, reproductive ratio was strongly correlated with root: shoot ratio $(r=-0.87$; $P<0.0001$; Fig. 4b).

\section{DisCUSSION}

Introduced North American and native European populations of Hypericum perforatum differed in their mycorrhizal responsiveness. While populations from both continents profited from inoculation with a cosmopolitan arbuscular mycorrhizal (AM) fungal species, North American populations benefited less than did European populations. North American populations also had finer root systems, more investment in reproductive biomass, and less investment in belowground biomass than European populations. These differences in mycorrhizal response, root architecture, and allocation patterns between populations and continents are likely genetically based as (1) populations from both continents were grown within a common environment; (2) previous work with $H$. perforatum has shown that strong founder effects are unlikely (Maron et al. 2004b); and (3) maternal effects were minimized statistically. The genetic basis of mycorrhizal respon- siveness has been observed in several agricultural species, such as wheat (Hetrick et al. 1992a), maize (Kaeppler et al. 2000), and rice (Gao et al. 2007), and in wild species such as big bluestem (Schultz et al. 2001). To our knowledge, this is the first evidence of a genetic shift in dependence on a mutualism following invasion.

We tested the responsiveness of $H$. perforatum to inoculation with AM fungi isolated from North American soil because the response to North American inoculum is the most relevant to considerations of genetic changes during the invasion process. Although we only measured responses to one species of AM fungi (Glomus mosseae), we believe our results are indicative of general differences in mycorrhizal dependence between native and introduced $H$. perforatum. We base this conclusion on several considerations. First, North American $H$. perforatum populations had finer root systems, with smaller average root diameter and more branching than European populations. There is a wellestablished trade-off between fine-root architecture and mycorrhizal responsiveness: fine root systems are typical of species (Baylis 1975, Hetrick et al. 1992a,b) and genotypes (Hetrick et al. 1992a, Schultz et al. 2001) with low mycorrhizal responsiveness. Indeed, we found that mycorrhizal response was negatively correlated with root branching within both continents (Fig. 4), as would be expected if mycorrhizal response was physiologically dependent upon root architecture (Baylis 1975, Schultz et al. 2001). Since our measurement of root architecture was made in AM fungi-free soil, finer root systems in North American populations likely indicate a generalized reduction in mycorrhizal response rather than simply a difference in response to G. mosseae. Second, $G$. mosseae is a cosmopolitan species commonly found in both Europe and North America (INVAM 2007). Thus, $H$. perforatum populations from both continents have likely been exposed to this species in their evolutionary history. Third, although the responsiveness of an 

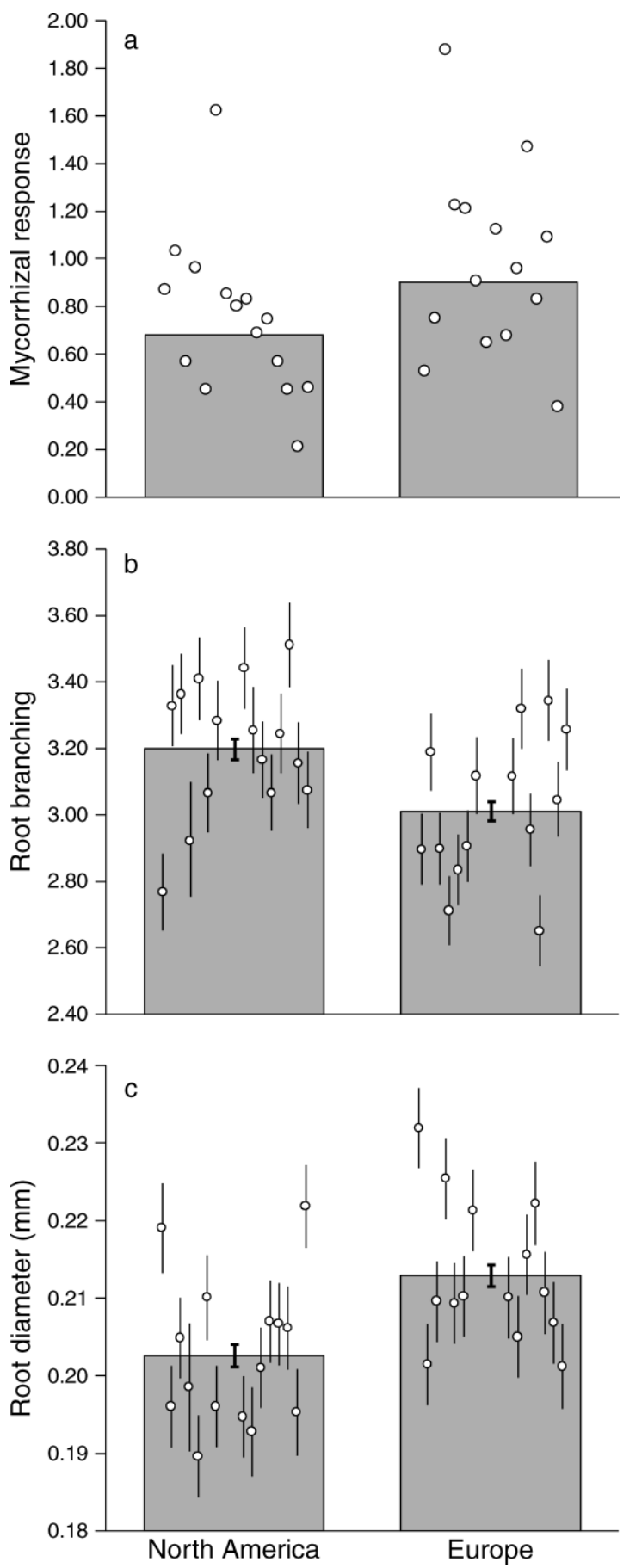

FIG. 2. (a) Mycorrhizal response [(inoculated - uninoculated)/uninoculated], (b) root branching, and (c) root diameter of Hypericum perforatum plants from North America (introduced) and Europe (native). Circles represent population means; error bars are \pm SE. North American populations had significantly lower mycorrhizal response and finer root systems, with more branching and smaller mean root diameter than European populations. individual plant species can vary depending on AM fungal species (Bever 2002, Klironomos 2003), such specificity of plant response does not generally overwhelm overall differences in responsiveness between plant species (Pringle and Bever 2008) and plant genotypes (A. E. Bennett and J. D. Bever, personal communications). Finally, our results are consistent with those from a multi-year common-garden experiment in Spain (Maron et al. 2004a), which demonstrated that European populations of $H$. perforatum were more negatively affected by soil fungicide than were North American populations, despite an overall reduction in pathogen infection and pathogen-induced mortality with fungicide application. Thus, although estimates of overall mycorrhizal responsiveness based on one greenhouse experiment utilizing a single fungal species are
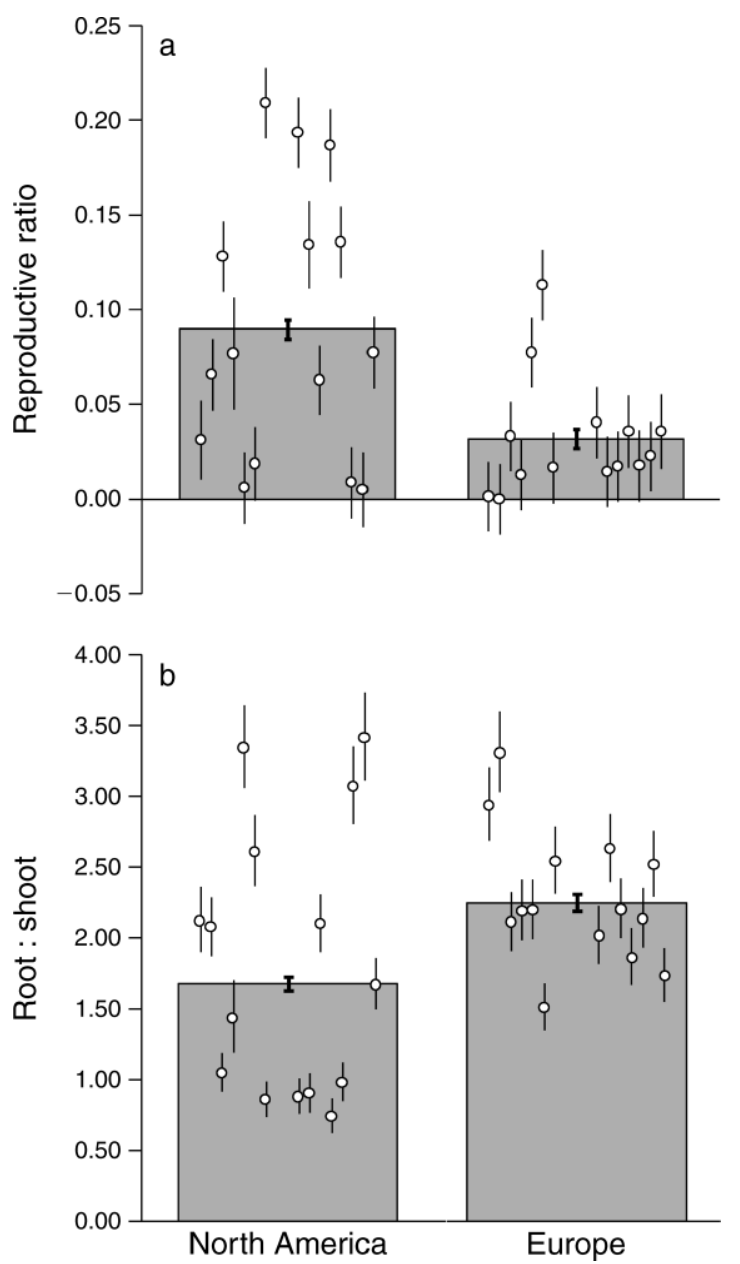

FIG. 3. (a) Mean ratio of reproductive biomass to total biomass, and (b) natural $\log$ of the root:shoot ratio of Hypericum perforatum plants from North America (introduced) and Europe (native). Circles represent population means; both sets of error bars are \pm SE. North American populations allocated significantly more biomass to first-year reproduction and had higher root: shoot ratios than did European populations. 

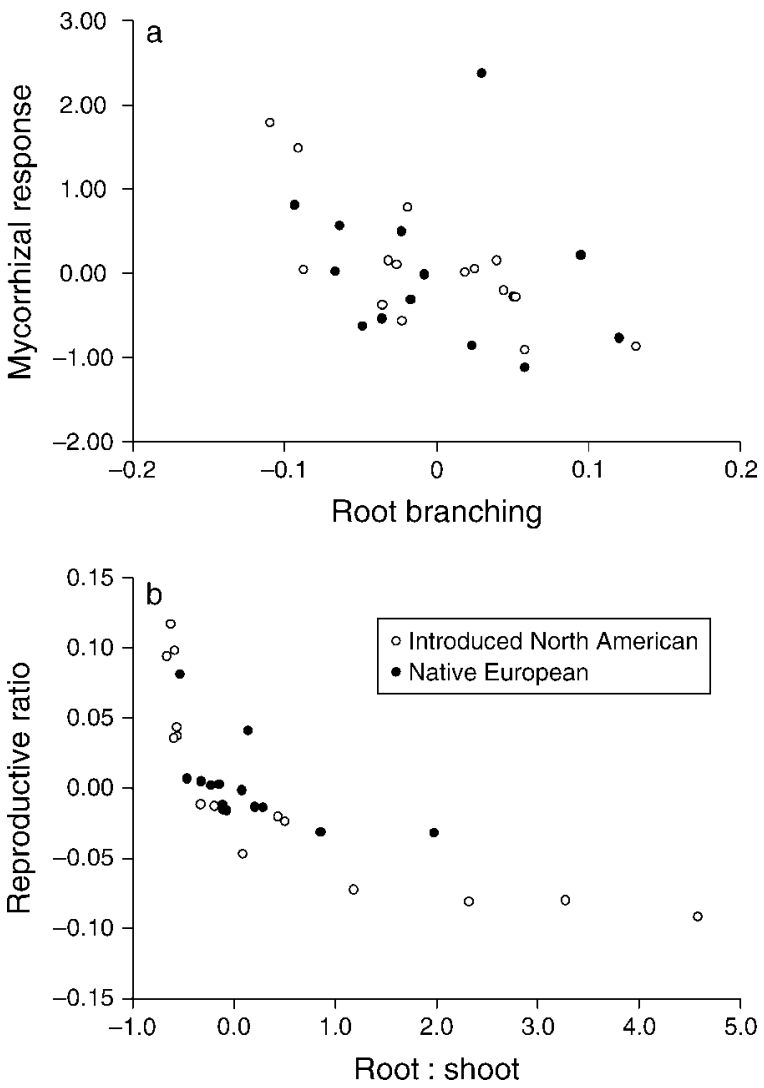

FIG. 4. (a) Mycorrhizal response vs. root branching, and (b) reproductive ratio vs. root:shoot ratio for introduced and native Hypericum perforatum populations. Effect of continent and initial size was removed using analysis of covariance, with the resulting residuals being centered on zero. There is a significant interpopulation genetic correlation between mycorrhizal response and root branching $(r=-0.48, P=0.009)$ and reproductive and root-shoot ratio $(r=-0.87, P<0.0001)$.

imperfect (Janos 2007), the observed difference in mycorrhizal responsiveness coupled with shifts in root architecture between North American and European $H$. perforatum strongly suggests a generalized reduction in mycorrhizal dependence in North America.

Hypericum perforatum populations from North America and Europe were similar in overall size, but differed significantly in allocation patterns. North American populations allocated less biomass to their roots and more to first-year reproduction than did European populations. These genetic changes in allocation patterns are consistent with a shift towards a more annual, weedier life history, which has been observed in other introduced species. While North American and European populations of $H$. perforatum did not differ in fecundity in a common-garden study (Maron et al. 2004b), similar shifts in allocation patterns have been observed in the root:shoot ratio of Lythrum salicaria (purple loosestrife; Bastlová and Květ 2002), and the reproductive effort of Silene latifolia (Blair and Wolfe 2004) and Sapium sebiferum (Chinese tallow tree;
Siemann and Rogers 2001). In these species, escape from herbivore and pathogen pressures in their introduced ranges may have relaxed evolutionary constraints on life-history traits, allowing the species to become weedier than in their native ranges.

Evolutionary changes in mycorrhizal responsiveness and root morphology have never been associated with changes in life history as they are in $H$. perforatum. While these parallel changes are consistent with expectations from a genetic correlation between these traits, life-history allocation was uncorrelated with both mycorrhizal response and root architecture, indicating that evolutionary change in mycorrhizal response is independent of evolutionary change in allocation to reproduction or perennial root structures. Moreover, given that $H$. perforatum has been introduced to North America multiple times (Maron et al. 2004b), it is unlikely that these evolutionary shifts were caused by a genetic bottleneck during the introduction of the species to North America. Rather, these parallel, yet independent, shifts in mycorrhizal response and life-history allocation are likely a result of inherent differences in selective pressures between the continents.

One such selective pressure could be higher soilnutrient availability in North America than in Europe. Differences in mycorrhizal dependence have been attributed to variation in soil nutrient conditions resulting in ecotypic adaptation; nutrient-poor soils result in increased dependence on AM fungi (Schultz et al. 2001). In nutrient-rich soils, excessive dependence on AM fungi does not benefit the plant, since it is more efficient to obtain nutrients directly from the soil by investing in finer root architecture (Hetrick et al. 1992b, Schultz et al. 2001). However, the number of populations and their geographic extent within each continent makes it unlikely that nutrient conditions are the sole factor driving the reduced mycorrhizal responsiveness and finer root architecture observed in North American populations of $H$. perforatum.

Another possibility is that anthropogenic degradation of the AM fungal community played a central role in the evolution of reduced dependence during the invasion of North America. In support of this hypothesis, we note that agricultural intensification, with its tillage, annual monocropping, and fertilization, can reduce the density and diversity of AM fungi (Oehl et al. 2003), as well as select for less beneficial species of AM fungi (Modjo and Hendrix 1986, Johnson 1993). Overgrazing can result in a similar degradation of the AM fungal community (Eom et al. 2001). These degraded mycorrhizal environments are expected to favor plant species and genotypes with reduced dependence on AM fungi. Consequently, the reduced AM fungal dependence observed in many agricultural species relative to their wild counterparts (Tawaraya 2003) likely evolved as a result of AM fungal-community degradation.

Agricultural intensification could therefore select for reduced dependence on AM fungi in both North 
American and European plant populations. However, given Europe's long history of intensive agriculture, we expect native European plant species to have evolved reduced mycorrhizal dependence relative to native North American species. Given that plants with high mycorrhizal dependence are at a disadvantage in AM fungi-poor environments (Reeves et al. 1979, Miller 1987), this reduced dependence may have then provided European plants a competitive advantage in the relatively new post-agricultural environments of North America. In support of this hypothesis, introduced species have been found to be generally less dependent on AM fungi than native species in southern California (Vogelsang and Bever 2009, Vogelsang et al. 2004). Moreover, pre-adaptation to anthropogenic habitats was long ago proposed as an explanation for the success of European weeds in New England (Gray 1879). While in Europe, forbs like $H$. perforatum occupy both heavily impacted post-agricultural environments, as well as environments that experienced relatively little human impact (Gibson and Brown 1991), in North America, their habitat is mainly restricted to disturbed areas. Given this difference in the "average" $H$. perforatum habitat between continents, it is possible that the evolution of further reductions in mycorrhizal dependence observed in North American populations of $H$. perforatum reflects adaptive specialization to anthropogenically disturbed habitats in North America. The increased allocation to first-year reproduction and reduced belowground allocation in North American populations of $H$. perforatum, a second facet of increased weediness, may also represent an adaptation to anthropogenic disturbance.

Regardless of the mechanisms contributing to the life history, root architecture, and mycorrhizal-responsiveness shifts in North American populations of $H$. perforatum, this study clearly suggests that post-introduction evolution played an important role in the establishment of the species in North America. Furthermore, it is also evident that changes in the dynamics of generalized mutualistic relationships may be more important in determining which species successfully establish in novel environments than previously understood.

\section{ACKNOWLEDGMENTS}

Our manuscript was improved by comments of H. Reynolds, P. Schultz, and members of the Bever-Schultz laboratory group. We acknowledge support from NSF grants DEB-0049080 and DEB-0616891 to J. D. Bever and DEB-0318719 to J. L. Maron.

\section{Literature Cited}

Baker, H. G. 1974. The evolution of weeds. Annual Review of Ecology and Systematics 5:1-24.

Bastlová, D., and J. Květ. 2002. Differences in dry weight partitioning and flowering phenology between native and non-native plants of purple loosestrife (Lythrum salicaria L.). Flora 197:332-340.

Baylis, G. T. S. 1975. The magnolioid mycorrhiza and mycotrophy in root systems derived from it. Pages 373-389 in F. E. Sanders, B. Mosse, and P. B. Tinker, editors.
Endomycorrhizas. Academic Press, New York, New York, USA.

Bever, J. D. 2002. Negative feedback within a mutualism: hostspecific growth of mycorrhizal fungi reduces plant benefit. Proceedings of the Royal Society of Londan B 269:25952601.

Blair, A. C., and L. M. Wolfe. 2004. The evolution of an invasive plant: an experimental study with Silene latifolia. Ecology 85:3035-3042.

Blossey, B., and R. Nötzold. 1995. Evolution of increased competitive ability in invasive nonindigenous plants: a hypothesis. Journal of Ecology 83:887-889.

Bossdorf, O., H. Auge, L. Lafuma, W. E. Rogers, E. Siemann, and D. Prati. 2005. Phenotypic and genetic differentiation between native and introduced plant populations. Oecologia 144:1-11.

Eom, A., G. W. T. Wilson, and D. C. Hartnett. 2001. Effects of ungulate grazers on arbuscular mycorrhizal symbiosis and fungal community structure in a tallgrass prairie. Mycologia 93:233-242.

Gao, X., T. W. Kuyper, C. Zou, F. Zhang, and E. Hoffland. 2007. Mycorrhizal responsiveness of aerobic rice genotypes is negatively correlated with their zinc uptake when nonmycorrhizal. Plant and Soil 290:283-291.

Gibson, C. W. D., and V. K. Brown. 1991. The nature and rate of development of calcareous grasslands in Southern Britain. Biological Conservation 58:297-316.

Gray, A. S. A. 1879. The pertinacity and predominance of weeds. American Journal of Science and Arts 18:161-167.

Hetrick, B. A. D., G. W. T. Wilson, and T. S. Cox. $1992 a$. Mycorrhizal dependence of modern wheat varieties, landraces, and ancestors. Canadian Journal of Botany 70:20322040.

Hetrick, B. A. D., G. W. T. Wilson, and T. C. Todd. $1992 b$. Relationships of mycorrhizal symbiosis, rooting strategy, and phenology among tallgrass prairie forbs. Canadian Journal of Botany 70:1521-1528.

INVAM [International Culture Collection of VA Mycorrhizal Fungi]. 2007. International Culture Collection of (Vesicular) Arbuscular Mycorrhizal Fungi. 〈http://invam.caf.wvu.edu/>

Janos, D. P. 2007. Plant responsiveness to mycorrhizas differs from dependence upon mycorrhizas. Mycorrhiza 17:75-91.

Johnson, N. C. 1993. Can fertilization of soil select less mutualistic mycorrhizae? Ecological Applications 3:749-757.

Johnson, N. C., J. H. Graham, and F. A. Smith. 1997. Functioning of mycorrhizal associations along the mutualism-parasitism continuum. New Phytologist 135:575-585.

Kaeppler, S. M., J. L. Parke, S. M. Mueller, L. Senior, C. Stuber, and W. F. Tracy. 2000. Variation among maize inbred lines of quantitative trait loci for growth at low phosphorus and responsiveness to arbuscular mycorrhizal fungi. Crop Science 40:358-364.

Klironomos, J. N. 2003. Variation in plant response to native and exotic arbuscular mycorrhizal fungi. Ecology 84:22922301.

Lee, C. E. 2002. Evolutionary genetics of invasive species. Trends in Ecology and Evolution 17:386-391.

Marler, M. J., C. A. Zabinski, and R. M. Callaway. 1999. Mycorrhizae indirectly enhance competitive effects of an invasive forb on a native bunchgrass. Ecology 80:1180-1186.

Maron, J. L., M. Vila, and J. Arnason. 2004a. Loss of enemy resistance among introduced populations of St. John's Wort (Hypericum perforatum). Ecology 85:3243-3253.

Maron, J. L., M. Vila, R. Bommarco, S. Elmendorf, and P. Beardsley. 2004b. Rapid evolution in an invasive plant. Ecological Monographs 74:261-280.

Mayo, G. M., and P. Langridge. 2003. Modes of reproduction in Australian populations of Hypericum perforatum L. (St. John's wort) revealed by DNA fingerprinting and cytological methods. Genome 46:573-579. 
McGonigle, T. P., M. H. Miller, D. G. Evans, G. L. Farichild and J. A. Swan. 1990. A new method which gives an objective measure of colonization of roots by vesicular arbuscular mycorrhizal fungi. New Phytologist 115:495-501.

Miller, R. M. 1987. Mycorrhizae and succession. Pages 205-219 in W. R. Jordan, M. E. Gilpin, and J. D. Aber, editors. Restoration ecology: a synthetic approach to ecological research. Cambridge University Press, Cambridge, UK.

Mitchell, C. E., et al. 2006. Biotic interactions and plant invasions. Ecology Letters 9:726-740.

Modjo, H. S., and J. W. Hendrix. 1986. The mycorrhizal fungus Glomus macrocarpum as a cause of tobacco stunt disease. Phytopathology 76:688-691.

Moora, M., and M. Zobel. 1998. Can arbuscular mycorrhiza change the effect of root competition between conspecific plants of different ages? Canadian Journal of Botany 76:613619.

Muhlenberg, H. 1793. Index florae Lancastriensis. Transactions of the American Philosophical Society 3:157-184.

Oehl, F., E. Sieverding, K. Ineichen, P. Mäder, T. Boller, and A. Wiemken. 2003. Impact of land use intensity on the species diversity of arbuscular mycorrhizal fungi in agroecosystems of central Europe. Applied and Environmental Microbiology 69:2816-2824.

Pank, F., F. Matzk, U. Kästner, W. D. Blüthner, E. F. de Garcia, A. Meister, U. Ryschka, and G. Schmann. 2003. Reproductive diversity and strategies for breeding in St. John's wort (Hypericum perforatum L.). Euphytica 134:7784.

Pringle, A., and J. D. Bever. 2008. Analogous effects of arbuscular mycorrhizal fungi in the laboratory and a North Carolina field. New Phytologist 108:162-175.

Pyšek, P. 1998. Is there a taxonomic pattern to plant invasions? Oikos 82:282-294

Reeves, F. B., D. Wagner, T. Moorman, and J. Kiel. 1979. The role of endomycorrhizae in revegetation practices in the semiarid West. I. A comparison of incidence of mycorrhizae in severely disturbed vs. natural environments. American Journal of Botany 66:6-13.
Régent Instruments. 2005. WinRhizo, version 2005c. Régent Instruments, Saint-Foy, Quebec, Canada.

Reinhart, K. O., and R. M. Callaway. 2006. Soil biota and invasive plants. New Phytologist 170:445-457.

Richardson, D. M., N. Allsopp, C. M. D'Antonio, S. J. Milton, and M. Rejmánek. 2000. Plant invasions - the role of mutualisms. Biological Reviews 75:65-93.

Sakai, A. K., et al. 2001. The population biology of invasive species. Annual Review of Ecology and Systematics 32:305332.

Sampson, A. W., and K. W. Parker. 1930. St. Johnswort on range lands of California. Bulletin 503. California Agriculture Experiment Station, Berkeley, California, USA.

SAS Institute. 2003. SAS system for linear models. SAS Institute, Cary, North Carolina, USA.

Schultz, P. A., R. M. Miller, J. D. Jastrow, C. V. Rivetta, and J. D. Bever. 2001. Evidence of a mycorrhizal mechanism for the adaptation of Andropogon gerardii (Poaceae) to high- and low-nutrient prairies. American Journal of Botany 88:1650 1656.

Siemann, E., and W. E. Rogers. 2001. Genetic differences in growth of an invasive tree species. Ecology Letters 4:514-518

Sokal, R. R., and F. J. Rohlf. 1995. Biometry: The principles and practice of statistics in biological research. Third edition. W. H. Freeman and Company, New York, New York, USA.

Tawaraya, K. 2003. Arbuscular mycorrhizal dependency of different plant species and cultivars. Soil Science and Plant Nutrition 49:655-668.

Vogelsang, K. M., and J. D. Bever. 2009. Mycorrhizal densities decline in association with nonnative plants and contribute to plant invasion. Ecology 90:399-407.

Vogelsang, K. M., J. D. Bever, M. Griswold, and P. A. Schultz. 2004. The use of mycorrhizal fungi in erosion control applications. Final Report for Caltrans. Contract number 65A0070. California Department of Transportation, Sacramento, California, USA.

Vogelsang, K. M., H. L. Reynolds, and J. D. Bever. 2006. Mycorrhizal fungal identity and richness determine the diversity and productivity of a tallgrass prairie system. New Phytologist 172:554-562.

\section{APPENDIX}

Locations of North American and European Hypericum perforatum populations (Ecological Archives E090-068-A1). 